\title{
Burnout amongst urban secondary school teachers in Namibia
}

Authors:
Dap Louw ${ }^{1}$
Evy George $^{1}$
Karel Esterhuyse ${ }^{1}$
Affiliations:
${ }^{1}$ Department of Psychology,
University of the Free State,
South Africa
Correspondence to:
Dap Louw
Email:
louwda@ufs.ac.za
Postal address:
PO Box 339, Bloemfontein
9301, South Africa
Dates:
Received: 05 June 2006
Accepted: 10 Sept. 2009
Published: [to be released]
How to cite this article:
Louw, D.A., George, E.,
\&urnout amongst urban
secondary school teachers
in Namibia. SA Journal of
Industrial Psychology/SA
Tydskrif vir Bedryfsielkunde,
37(1), Art. \#1008, 7 pages.
doi:10.4102/sajip.v37i1.1008

(C) 2011. The Authors. Licensee: AOSIS OpenJournals. This work is licensed under the Creative Commons Attribution License.
Orientation: Burnout seems to be particularly common amongst professionals who help and enable people to cope with the demands of their daily lives.

Motivation for the study: The study focused on the magnitude and nature of burnout amongst Namibian teachers as well as the influence of biographical factors on their levels of burnout. Another aim was to determine the extent to which the results of this study correlate with research findings in other countries.

Research design, approach and method: The researchers used a non-experimental research method. The study involved more than 300 secondary school teachers from the Windhoek region of Namibia. They administered the Maslach Burnout Inventory (MBI) and a biographical questionnaire to achieve the goals of the study.

Main findings: The main findings of the study were that the participants experienced similar levels of burnout compared to teachers in other countries. This was especially true for emotional exhaustion. Teaching experience was the biographical variable that yielded the most significant positive correlation with burnout.

Practical/managerial implications: The education authorities should address the emotional needs of secondary school teachers in Namibia urgently. They should introduce effective burnout intervention and prevention programmes. These programmes could result in higher levels of job satisfaction and educational effectiveness. They could also lead to increased general fulfilment and better teacher retention.

\section{Introduction}

Burnout has become a widely researched phenomenon since Freudenberger (1974) first used the term to describe the symptoms of physical, psychological and behavioural exhaustion that occurs in the work situation.

Burnout can occur in all professions. However, it seems to be particularly common amongst professionals who help and enable people to cope with the demands of their daily lives (Gavish \& Friedman 2010; McCormick, 2011; Pines, 2002; Rakovec-Felser, 2011). Therefore, professionals like teachers, doctors and mental health workers should have special professional skills and an exceptional ability to deal with the stressors they incur because of the emotionally demanding nature of their professions. If they do not, the result is often emotional exhaustion, depersonalisation and a reduced sense of personal accomplishment. These, according to Brouwers, Tomic, and Boluijt (2011) and Maslach (1982), are the classical symptoms of burnout.

\section{Biographical variables}

The most frequently researched biographical variables that researchers have noted as potential causal factors for burnout are gender, age and teaching experience, marital status and level of education.

\section{Gender}

Beer and Beer (1992) maintain that men and women experience burnout in similar ways. The essential differences lie in what they experience as stressors. For men, the sources of stress centre on the work environment and relate to the gap they experience between individual and environmental demands. Women find that time is the major source of stress. Time management, in coping with their family and career demands, becomes difficult and causes role conflict.

The research that Decker and Borgen (1993) conducted supports the significance of gender differences in burnout. A study amongst primary and secondary school teachers in Greece 
found that women teachers experienced higher levels of occupational stress compared to men (Antoniou, Polychroni \& Vlachakis, 2006). Most studies report higher levels of emotional exhaustion (a component of burnout) amongst women and higher levels of depersonalisation (another component of burnout) amongst men (Purvanova \& Muros, 2010; Smit, 2007).

\section{Age and teaching experience}

There appears to be a clear relationship between age and burnout. Smit (2007) reports that, of all the demographic variables, age links most consistently to burnout.

Research shows that younger employees are the most susceptible to burnout (Antoniou, Polychroni \& Walters, 2000; Luk, Chan, Selwyne, Cheong \& Ko, 2010). Young teachers, who are new in the profession, tend to be idealistic and are often very anxious to perform and achieve professionally (Gibbs, 2010; Friedman, 2000). When they fail to reach their students, they feel undervalued and unappreciated in their performance. They feel more anxious and inadequate and become vulnerable to burnout (Daniel \& Schuller, 2000; Tynjälä \& Heikkinen, 2011).

Byrne (1998), Hughes (2001) and Vanheule (2001) suggest that teachers, who stay in the profession after they become disillusioned, ultimately burn out after before their 10th consecutive teaching year. This suggests that burnout increases with age and the length of time they spend teaching whilst feeling intrinsically unhappy. However, Burke and Greenglass (1993) found that age was not significant in teacher burnout.

\section{Marital status}

Research yielded differing results about marital status and burnout. Those who are unmarried (especially men) seem to be more prone to burnout compared to those who are married (Erşan, Doğa \& Doğan, 2011; McDermott, 1984; Maslach \& Jackson, 1985). On the other hand, Sears and Navin (1983) found no significant correlation between marital status and burnout.

\section{Level of education}

Teachers with higher levels of education tend to have higher expectations about what they want to achieve. Failing to meet these expectations makes them prone to burnout (Maslach, 1982). In addition, Altun, Çağlar and Yazici (2011) and Schaufeli and Enzmann (1998) found that employees with higher levels of education are more susceptible to burnout.

Although there is no known research on teacher burnout in Namibia, personal experience and conversations with teachers in Namibian schools suggested that there is a similar situation there. The authors accept that the variables responsible for teacher burnout in other countries may also apply in Namibia.

However, another additional and unique factor that has made a significant contribution to the Namibian context is its independence in 1990. Namibia was a mandate of South
Africa after 1915. Therefore, it was also subject to the apartheid system. After independence, there have been many changes in the education system. Most of these transformations aimed to rectify the injustices of apartheid and were necessary. However, a lack of efficient preparation for these changes made it difficult for teachers to cope in many cases.

Against this background, the present study focused on the magnitude and nature of burnout amongst Namibian teachers. It also aimed to determine the extent to which they correlate with research findings in other countries.

\section{Research design \\ Research method \\ Participants}

The researchers decided, for practical reasons, to include only teachers from secondary schools in Windhoek, the capital of Namibia. The director of the Windhoek region, one of the education regions in Namibia, granted permission for the study. The researchers randomly selected 480 teachers from the 17 state schools in Windhoek to participate in the study.

The researchers included teachers and management body members in the sample. A covering letter, which explained the purpose of the study to the participants, accompanied each set of questionnaires. The questionnaires consisted of a biographical questionnaire and the Maslach Burnout Inventory (MBI). The researchers contacted the principals of the schools about the study. They delivered the sets of questionnaires personally to the participating schools where they were distributed to the teachers and collected after completion.

A total of 337 participants responded. This is a response rate of $70 \%$. The researchers measured all biographical variables the study investigated, with the exception of age, using a nominal scale. For the analyses that follow, the researchers decided to divide the teachers' ages into 30 and younger, 3140 and older than 40 . The average age of the research group was 37.62 and had a standard deviation of 8.95 . The youngest teacher in the research group was 23 and the oldest 60 .

The researchers calculated information about the distribution of the 337 teachers on the seven biographical variables using the SAS computer program (SAS Institute, 1985). Table 1 gives the distribution.

One should note that, for practical reasons, the researchers grouped some of the original categories of a specific biographical variable so that they could use them meaningfully in the analyses.

Table 1 shows that approximately two thirds of the participants were women, most of whom were married. There were slightly more teachers from the average resourced than from the above-average resourced schools. The different categories of participants in the group had relatively equal periods of experience. Most participants were not in management positions. Approximately two thirds of the group held a bachelor degree or higher. 
TABLE 1: Frequency distribution of biographical variables.

\begin{tabular}{|c|c|c|}
\hline Biographical variables & $\boldsymbol{F}$ & $\%$ \\
\hline \multicolumn{3}{|l|}{ Gender } \\
\hline Male & 112 & 33.2 \\
\hline Female & 225 & 66.8 \\
\hline \multicolumn{3}{|l|}{ Age } \\
\hline 30 and younger & 85 & 25.2 \\
\hline $31-40$ & 136 & 40.4 \\
\hline Older than 40 & 116 & 34.4 \\
\hline \multicolumn{3}{|l|}{ Marital status } \\
\hline Married & 210 & 62.3 \\
\hline Single & 127 & 37.7 \\
\hline \multicolumn{3}{|l|}{ School area } \\
\hline Average resourced (less resourced) & 186 & 55.2 \\
\hline Above-average resourced & 151 & 44.8 \\
\hline \multicolumn{3}{|l|}{ Teaching experience } \\
\hline 5 years and less & 87 & 25.8 \\
\hline $6-10$ years & 72 & 21.4 \\
\hline $11-15$ years & 83 & 24.6 \\
\hline More than 15 years & 95 & 28.2 \\
\hline \multicolumn{3}{|l|}{ Highest academic qualification } \\
\hline Diploma or lower & 119 & 35.3 \\
\hline Bachelor degree or higher & 218 & 64.7 \\
\hline \multicolumn{3}{|l|}{ Rank } \\
\hline Non-management & 286 & 84.9 \\
\hline Management & 51 & 15.1 \\
\hline
\end{tabular}

$F$, frequency.

TABLE 2: Cronbach's alpha coefficients for the subscales of the Maslach Burnout Inventory.

\begin{tabular}{lc}
\hline Questionnaire construct & $\boldsymbol{\alpha}$ coefficients \\
\hline Emotional exhaustion & 0.9128 \\
Depersonalisation & 0.7442 \\
Personal accomplishment & 0.8105 \\
\hline
\end{tabular}

$\alpha$, Cronbach alpha.

\section{Measuring instruments}

The researchers used the measuring instruments that follow to achieve the empirical aims of the study:

Biographical questionnaire: The researchers used a selfcompiled questionnaire to collect data on gender, age, marital status, school area, teaching experience, qualifications and rank.

The Maslach Burnout Inventory: The researchers measured teacher burnout using the MBI (Maslach \& Jackson, 1986; Maslach, Jackson \& Leiter, 1996).

The MBI is fairly reliable and valid. For example, Cronbach alpha coefficients that range between 0.70 and 0.90 have been reported for the three subscales (Maslach, Jackson \& Leiter, 1996; Wheeler, Vassar, Worley \& Barnes, 2011). Researchers have reported similar psychometric properties for South Africa (Jeena, 1998; Mostert \& Rothman, 2006; Sadiwalla, 2004; Rutsch, 1997; Van der Linde, Van der Westhuizen \& Wissing, 1999).

Because the MBI was standardised in the United States of America (USA) and no psychometric information was available for Namibians, the researchers decided to determine the reliability of the MBI for the present study by investigating its internal consistency for this population. They did this by calculating Cronbach's alpha coefficients using the SPSS computer program (SPSS Incorporated, 1983). Table 2 gives the coefficients.

The coefficients in Table 2 show that the subscales of the MBI produce acceptable to high internal consistent measures. This made it a valid instrument for this study. The researchers formulated the hypothesis that follows.

The biographical variables of gender, age, marital status, type of school, teaching experience and academic qualifications have a significant influence on the average burnout scores of Namibian teachers.

\section{Statistical procedures}

The researchers compared the levels of burnout of the teachers using all seven biographical variables.

As Table 2 shows, the researchers divided some of the biographical variables (gender, marital status, school area, qualifications and rank) into only two categories, whereas they divided age and teaching experience into three categories. Consequently, the researchers used different statistical procedures to test the hypothesis.

When there were only two categories for a specific biographical variable, the researchers used the Hotelling $T^{2}$ test for independent groups (Tabachnick \& Fidell, 1989). For the variables for which they obtained statistically significant $T^{2}$ values, they evaluated the differences further using post hoc $t$-tests.

When there were more than two categories for a biographical variable, the researchers performed a multivariate variance analysis (MANOVA). When they obtained a significant result ( $F$ value) with the MANOVA analysis, they followed it with a one-way analysis of variance. Because they considered more than two categories (subgroups) per biographical variable, they used the Scheffé procedure to determine which of the average scores on the dependent variables of the subgroups showed a statistically significant difference. With MANOVA analyses, the assumptions that follow are the basis of statistical inferences:

- the data set will have to originate from a multi-variate normal population

- the data set will have equal subgroup covariance matrices

- the subgroups are a collection of the various independent data sets (Du Toit \& Stumpf, 1982).

With regard to the first assumption, we can accept with relative certainty that the data set comes from a multi-variate normal population. The lowest number of observations per level of the three independent variables is 51 and conforms to the central limit theorem (Huysamen, 1993). Therefore, we can assume that the means of the subpopulation have approximate multivariate normal distributions. 
To determine whether the data set satisfies the conditions for the second assumption, that of equal subgroup covariance matrices, the researchers used a section of the SAS-DISCRIM procedure (SAS Institute, 1985). When one obtains a significant value with this procedure, it indicates uneven subgroup covariance matrices. The researchers used both the $1 \%$ and the $5 \%$ levels of significance in this study.

As far as the third assumption is concerned, it appears from the research design that the subgroups were mutually independent.

\section{Results}

Before discussing the results that are relevant to the research hypothesis, the researchers will discuss briefly the descriptive statistics (means and standard deviations) of the relevant dependent variables for the research group to provide background. They will then investigate the burnout profiles.

\section{Descriptive statistics}

Table 3 presents the results on burnout. The results of the Namibian teachers' higher level of emotional exhaustion (compared to depersonalisation and personal accomplishment) correspond with those of teachers in the USA (Maslach \& Jackson, 1986; Schermuly, Schermuly \& Meyer, 2011), South Africa (Van der Linde, Van der Westhuizen \& Wissing, 1999) and Turkey (Gursel, Sunbul \& Sari, 2002). This is also true for personal accomplishment. However, the findings suggest lower depersonalisation in Namibian teachers when compared to the results of Maslach and Jackson. A possible explanation for this is that two-thirds of the participants in the current study were women. Maslach and Jackson (1986) and Gursel et al. (2002) found that men teachers tend to score higher than women teachers do on the depersonalisation subscale. These authors attribute this gender difference to sex role socialisation that results in the different career expectations of men and women.

However, Bhadoria and Singh (2011) found the opposite. Female participants showed higher levels of depersonalisation. Variables, like cultural factors and concept interpretation, could have led to different findings and should be investigated.

\section{Burnout profiles}

To determine the level of burnout the Namibian teachers experienced, the researchers divided their scores on the three subscales of the MBI into low, average and high scores. They did this according to the guidelines in the MBI manual (Maslach \& Jackson, 1986). These findings appear in Table 4.

Table 4 shows that approximately a quarter of the teachers experienced high levels of emotional exhaustion, whilst only $12.2 \%$ experienced high levels of depersonalisation. Furthermore, about the same number of teachers experienced both low and high levels of personal accomplishment.
TABLE 3: Burnout results of the participants.

\begin{tabular}{lccc}
\hline Burnout variables & $\boldsymbol{N}$ & $\bar{X}$ & SD \\
\hline Emotional exhaustion & 337 & 19.71 & 12.85 \\
Depersonalisation & 337 & 6.66 & 8.68 \\
Personal accomplishment & 337 & 32.79 & 5.76 \\
\hline
\end{tabular}

$N$, numberof respondent; $\bar{X}$ denotes mean; SD, standard deviation.

TABLE 4: The participants' scores on the three components of the Maslach Burnout Inventory.

\begin{tabular}{|c|c|c|c|c|c|c|}
\hline \multirow[t]{2}{*}{ MBI subscale } & \multicolumn{2}{|c|}{ Low } & \multicolumn{2}{|c|}{ Average } & \multicolumn{2}{|c|}{ High } \\
\hline & $\%$ & $n$ & $\%$ & $n$ & $\%$ & $n$ \\
\hline Emotional exhaustion (ee) & 44.5 & 150 & 26.7 & 90 & 28.8 & 97 \\
\hline Depersonalisation (dp) & 67.4 & 227 & 20.4 & 69 & 12.2 & 41 \\
\hline Personal accomplishment (pa) & 36.5 & 123 & 25.8 & 87 & 37.7 & 127 \\
\hline
\end{tabular}

TABLE 5: Frequency distribution of teachers with high levels of emotional exhaustion.

\begin{tabular}{|c|c|c|}
\hline Biographical variable & $\begin{array}{l}\text { Emotional exhaustion } \\
\qquad(n=97)\end{array}$ & $\%$ \\
\hline \multicolumn{3}{|l|}{ Gender } \\
\hline Male & 29 & 25.9 \\
\hline Female & 68 & 30.2 \\
\hline \multicolumn{3}{|l|}{ Age } \\
\hline 30 and younger & 21 & 24.7 \\
\hline $31-40$ & 41 & 30.1 \\
\hline Older than 40 & 35 & 30.2 \\
\hline \multicolumn{3}{|l|}{ Marital status } \\
\hline Married & 55 & 26.2 \\
\hline Single & 42 & 33.1 \\
\hline \multicolumn{3}{|l|}{ School area } \\
\hline Average resourced (less resourced) & 50 & 26.9 \\
\hline Above-average resourced & 47 & 31.1 \\
\hline \multicolumn{3}{|l|}{ Teaching experience } \\
\hline 5 years and fewer & 18 & 20.7 \\
\hline $6-10$ years & 16 & 22.2 \\
\hline $11-15$ years & 32 & 38.6 \\
\hline More than 15 years & 31 & 32.6 \\
\hline \multicolumn{3}{|l|}{ Highest academic qualifications } \\
\hline Diploma or lower & 31 & 26.1 \\
\hline Bachelor degree or higher & 66 & 30.3 \\
\hline \multicolumn{3}{|l|}{ Rank } \\
\hline Non-management & 79 & 27.6 \\
\hline Management & 18 & 35.3 \\
\hline
\end{tabular}

$n$, number.

Most experienced low levels of depersonalisation whilst a relatively small percentage $(12.2 \%)$ had high levels of depersonalisation. Since emotional exhaustion is an important component of burnout, the researchers decided to describe only those teachers $(n=97)$ who experienced high levels of emotional exhaustion in terms of their biographical variables. This sample had twice as many women as men participants. Results from this study compare favourably with results in a study that Van der Linde et al. (1999) conducted on gender distributions.

Table 5 shows the frequency distribution of the high levels of emotional exhaustion in the group. Because different numbers of participants appear in the various categories of the biographical variables, the researchers calculated the 
number of teachers with high levels of emotional exhaustion as a percentage of the total number of teachers in each of the categories.

Table 5 shows that approximately a quarter of the teachers, regardless of which category of the biographical variables they fall into, experience a high degree of emotional exhaustion. Furthermore, the teachers who experience a high level of emotional exhaustion distribute relatively equally amongst the different categories of a specific biographical variable.

However, more teachers with more than 10 years of teaching experience had higher levels of emotional exhaustion than did teachers with 10 years and fewer of teaching experience. The results of the Namibian teachers' teaching experience correspond with the findings of studies in South Africa (Rutsch, 1997; Van der Linde et al., 1999) and other countries (Daniel \& Schuller, 2000; Friedman, 1991; Pedrabissi \& Rolland, 1993). However, other researchers have found no, or inverse, relationships between teaching experience and emotional exhaustion (Brackett, Palomere, Mojsa-Kaja \& Salovey, 2010; Gavish \& Friedman, 2010).

The same increased tendency in emotional exhaustion seemed to be present according to rank. Compared to teachers in non-management positions, more teachers in management positions experienced high levels of emotional exhaustion.

Researchers like Geving (2007), Grayson and Alvarez, 2008) and Wolters and Daugherty (2007) reached similar conclusions.

One could ascribe the higher levels of burnout of Namibian teachers in management positions to the fact that, next to being involved in instruction at higher-grade levels, they also have to deal with personnel, learners and parents and administrative issues. These factors make managers more prone to burnout.

\section{Hypothesis testing}

Most of the biographical variables consisted of only two categories. Here, the researchers used the Hotelling $T^{2}$ test to test the hypothesis. They used MANOVA where more than two categories for a biographical variable were involved.

The researchers compared the teachers' average scores on the burnout subscales for the seven biographical variables. For five of the seven biographical variables, there were only two categories per variable (gender, either male or female). The researchers dealt with these firstly by using the Hotelling $T^{2}$ test. They dealt with the remaining two biographical variables (age and experience), which consisted of three categories, afterwards.

The researchers compared the average burnout subscale scores for the biographical variables of gender, marital status, school area, highest qualifications and rank using the Hotelling $T^{2}$ test. They used the Bio-Medical Data Package BMDP programme to do so. Table 6 gives the results.
Table 6 shows that no calculated $T^{2}$ values were significant on at least the 5\% level. Therefore, one can assume that there were no significant differences in the average burnout subscale scores for the different groups according to the five biographical variables in the MBI subscale investigation. Similar studies, which Hock (1988), Smith and Leng (2003) and Vilakazi (2005) conducted on teachers, also yielded nonsignificant findings for the same biographical variables.

Hock maintains that the absence of significant findings for these demographical variables probably indicates that teachers in such a sample are either equally susceptible or resistant to burnout or that they experience similar levels of burnout.

The researchers followed these analyses by using the two biographical variables that consist of more than two categories. They applied MANOVA for this purpose. One needs to investigate the assumption of equal covariance matrices first before carrying out the MANOVA procedure.

The researchers used part of the SAS-DISCRIM procedure (SAS Institute, 1985) to do this. They investigated this assumption for both variables (age and experience) for the subscales of the MBI. The $\chi^{2}$ values for age and experience were 16.062 and 14.53 respectively. Both values were not significant and one can assume equal covariance matrices. Because the values also met this assumption, the researchers performed the MANOVA analyses using the SAS computer program (SAS Institute, 1985). Table 7 gives the results.

Table 7 shows that the researchers found no significant $F$ value for the age variable. Therefore, they did not investigate this variable further. However, there were differences in the average MBI subscale scores for teachers with different levels of experience (5 years and less, 6-10 years, 11-15 years and 16 years and more). These differences were significant on the $5 \%$ level.

The researchers investigated the nature of these differences by determining which dependent variable of the three subscales of the MBI showed significant differences for teachers with different experience levels. For this purpose, they conducted a one-way analysis of variance using the SAS computer program. Table 8 gives these results.

TABLE 6: Results of the five biographical variables on the Maslach Burnout Inventory subscales.

\begin{tabular}{lccc}
\hline Biographical variables & Hotelling $\boldsymbol{T}^{2}$ & $\boldsymbol{F}$-value & $\boldsymbol{p}$-value \\
\hline Gender & 2.939 & 0.974 & 0.4052 \\
Marital status & 3.929 & 1.302 & 0.7237 \\
School area & 7.282 & 2.413 & 0.0666 \\
Qualifications & 6.179 & 2.047 & 0.1071 \\
Rank & 1.580 & 0.524 & 0.6663 \\
\hline
\end{tabular}

$p$, probability value.

TABLE 7: MANOVA $F$ values for testing the main effects on the Maslach Burnout Inventory subscales.

\begin{tabular}{lccc}
\hline Source & $\boldsymbol{F}$-value & $\boldsymbol{v}$ & $\boldsymbol{p}$-value \\
\hline Age & 1.597 & 6.656 & 0.1454 \\
Experience & 2.101 & 9.983 & 0.0270 \\
\hline
\end{tabular}

$v$, degrees of freedom; $p$, probability value. 
Table 8 shows that there were significant differences on the $5 \%$ level for the emotional exhaustion variable. Because there were four groups with differing levels of experience (five years and fewer, 6-10 years, 11-15 years and 16 years and more) to consider, the researchers performed a post $t$-test (the Scheffé test) to identify the group differences. Table 9 gives the results for the emotional exhaustion subscale.

The Scheffé results show that the mean emotional exhaustion scores of teachers with five years and shorter experience (group 1) differ from those of teachers with experience of between 11 and 15 years (group 3).

Previous research supports this finding. It showed that, if teachers do not leave their jobs early and when they feel like doing so, they decide to stay in the profession despite their feelings of emotional exhaustion (Maslach, 1982; Skaalvik \& Skaalvik, 2011).

Byrne (1998) explains that emotional exhaustion can result from pre-teaching ideals that fade when the realities of the everyday classroom world face the teachers. If they remain in teaching, teachers resign themselves to do the best they can in the circumstances. Respondents in Byrne's study indicated that teachers experienced symptoms of burnout, especially in their seventh and then in their tenth year of teaching and had been fighting with burnout ever since.

As noted earlier, most of the teachers in this Namibian sample were women. As further possible explanations for the higher prevalence of emotional exhaustion in this study, Maslach and Jackson (1986), Gursel, Sunbul and Sari (2002) and Purvanova and Muros (2010) found that women teachers scored higher on emotional exhaustion than did men teachers.

\section{Discussion}

The main finding of this study was that secondary school teachers in Windhoek, Namibia, experience levels of burnout that compare with those in most other countries. This is especially true of their levels of emotional exhaustion, which measured higher than their levels of depersonalisation and

TABLE 8: Results of the one-way analysis of variance, with experience as the independent variable, on the three Maslach Burnout Inventory subscales.

\begin{tabular}{lcc}
\hline Variable & $\boldsymbol{F}$-value & $\boldsymbol{p}$-value \\
\hline Emotional exhaustion & 3.50 & 0.0159 \\
Depersonalisation & 1.64 & 0.1800 \\
Personal accomplishment & 1.26 & 0.2876 \\
\hline
\end{tabular}

$p$, probability value.

TABLE 9: Scheffé results for emotional exhaustion and experience as independent variables.

\begin{tabular}{lccc}
\hline Groups & $\boldsymbol{N}$ & $\chi^{2}$ value & SD \\
\hline 5 years and shorter (group 1) & 87 & 16.23 & 12.15 \\
6-10 years (group 2) & 72 & 18.58 & 12.51 \\
$11-15$ years (group 3) & 83 & 23.28 & 13.32 \\
16 years and longer (group 4) & 95 & 20.62 & 12.55 \\
\hline
\end{tabular}

Note: Group 1 and 3 differ

$N$, number; $\chi^{2}$, the calculated test statistic or chi squared statistic, SD, standard deviation of the sample. personal accomplishment. Teaching experience was the most significant biographical indicator associated with burnout. Gender, age, academic qualifications, rank, type of school and marital status did not yield significant results.

Although findings like these provide valuable information about the very real emotional needs of secondary school teachers in Namibia, they will only be of academic interest if the relevant education authorities do not take the necessary action, especially by introducing effective burnout intervention and prevention programmes. These programmes could result in higher levels of job satisfaction and educational effectiveness and lead to increased general fulfilment and better teacher retention.

This study suggested that teachers in management positions tend to experience higher levels of burnout than their nonmanagement colleagues do. Therefore, they might need support systems and effective management strategies so that teachers in management positions experience less stress.

Therefore, focusing on making management decisions more transparent and involving non-management teachers in decision-making and planning could contribute to a better work environment for all.

\section{Limitations of the study}

The present study has some limitations, which one should consider when interpreting the findings.

Firstly, the researchers collected data using quantitative research only. This does not seem to capture the complexity of teachers' perceptions of their workplace conditions. Therefore, a combination of quantitative and qualitative research would have been a better option. Focus group interviews could have helped to achieve a more behaviourally related assessment of the subjects' lives at work and a better indication of the exact factors that contribute to their levels of burnout.

Secondly, teachers in this study completed the questionnaires during the examination period in Namibia (April). This is usually a stressful time for teachers, especially those in management positions. This may have had an effect on their responses. They were preoccupied with duties relating to the examinations and this might have affected the return rate of the questionnaires.

Thirdly, the study did not consider the role of cultural factors in the findings. Namibia is a multicultural country with numerous ethnic groups and languages. The effect of cultural variables on human behaviour is well known and future research should consider it.

\section{Conclusion}

In conclusion, the researchers need to mention that continued research on teachers' levels of burnout could eventually lead to realistic and successful burnout interventions and 
prevention programmes. Teachers would then be more likely to stay in the teaching profession and find fulfilment in what they do.

The researchers hope that this study will stimulate more research on variables like those that this study has shown as significant.

\section{References}

Altun, F., Çağlar, S., \& Yazici, H. (2011). Some demographic variables and personal health behaviors of teachers. Procedia - Social and Behavioral Sciences, 15, 2314-2318.

Antoniou, A.S., Polychroni, F., \& Walters, B. (2000). Sources of stress and professional burnout of teachers of special educational needs in Greece. Paper presented at the International Special Education Congress, University of Manchester 24-28 July 2000. Retrieved 09 March 2007, from http://www.isec2000.org.uk/abstracts/ papers_p/polychroni_1.htm.

Beer, J., \& Beer, J. (1992). Burnout and stress, depression and self-esteem of teachers. Psychological Reports, 71, 1331-1336. http://dx.doi.org/10.2466/PR0.71.8.13311336, PMid:1480718.

Bhadoria, D., \& Singh, T. (2010). Relationships of Age and Gender with Burnout among Primary School Teachers. Indian Journal of Social Science Researches, 7(2), 10-17.

Brackett, M.A., Palomera, R., Mojsa-Kaja, J., Reyes, M.R., \& Salovey, P. (2010). Emotionregulation ability, burnout, and job satisfaction among British secondary-school teachers. Psychology in the Schools, 47(4), 406-417.

Brouwers, A., Tomic, A. \& Boluijt, H. (2011). Job demands, job control, social support and self-efficacy beliefs as determinants of burnout among physical education teachers. Europe's Journal of Psychology, 1, 17-39

Burke, R.J., \& Greenglass, E. (1993). Work stress, role conflict, social support, and psychological burnout among teachers. Psychological Reports, 73, 371-380.

Byrne, J.J. (1998). Teacher as hunger artist: Burnout: Its causes, effects and remedies. Contemporary Education, 69(2), 86-91.

Decker, P.J., \& Borgen, F.H. (1993). Dimensions of work appraisal. Journal of Counselling Psychology, 40, 470-478. http://dx.doi.org/10.1037/0022-0167.40.4.470

Du Toit, S.H.C., \& Stumpf, R.H. (1982). Riglyne by die ontleding van omvangryke datastelle [Guidelines for the analysis of comprehensive databases]. Pretoria: Human Sciences Research Council.

Erşan, E.E., Doğan, O., \& Doğan, S. (2011). Analyzing of factors related to burnout in health professionals of Sivas Numune Hospital. Cumhuriyet Medical Journal 33, health

Freudenberger, H.J. (1974). Staff burn-out. Journal of Social Issues, 30(1), 159-164. http://dx.doi.org/10.1111/j.1540-4560.1974.tb00706.x

Friedman, I.A. (1991). High- and Low-burnout Schools: School Culture Aspects of Teacher Burnout. Journal of Educational Research, 84(6), 325-333. http://dx.doi. org/10.1080/00220671.1991.9941813

Friedman, I.A. (1995). Measuring school principal-experienced burnout. Educationa and Psychological Measure, 55(4), 641-651. http://dx.doi.org/10.1177/0013164 495055004012

Friedman, I.A. (2000). Burnout in teachers: Shattered dreams of impeccable professional performance. Journal of Clinical Psychology, 56(5), 595-606. http:// dx.doi.org/10.1080/00220671.1991.9941813.

Gavish, B., \& Friedman, I.A. (2010). Novice teachers' experience of teaching: a dynamic aspect of burnout. Social Psychology of Education, 13, 141-167

Geving, A.M. (2007). Identifying the types of student and teacher behaviours associated with teacher stress. Teaching and Teacher Education, 23(5), 624-640.

Gibbs, B. (2010). Novice but Great. Talking About Teaching, 4, 47-53.

Grayson, J.L., \& Alvarez, H.K. (2008). School climate factors relating to teacher burnout: A mediator model. Teaching and Teacher Education 24(5), 1349-1363.

Gursel, M., Sunbul, M.A., \& Sari, H. (2002). An analysis of burnout and job satisfaction between Turkish headteachers and teachers. European Journal of Psychology of Education, 17(1), 35-45. http://dx.doi.org/10.1007/BF03173203

Hock, R.R. (1988). Professional burnout among public school teachers. Public personnel management, 17(2), 167-190.

Hughes, R.E. (2001). Deciding to leave but staying: Teacher burnout, precursors, and turnover. International Journal of Human Resource Management, 12(2), 288-298. http://dx.doi.org/10.1080/713769610, http://dx.doi. org/10.1080/09585190122429, http://dx.doi.org/10.1080/09585190010015097

Huysamen, G.K. (1993). Inferensiële statistiek en navorsingsontwerp: 'n Inleiding [Inferential statistics and research design: An introduction]. Cape Town: Academia.

lacovides, A., Fountoulakis, K.N., Kaprinis, St., \& Kaprinis, G. (2003). The relationship between job stress, burnout and clinical depression. Journal of Affective Disorders, 75(3), 209-221. http://dx.doi.org/10.1016/S0165-0327(02)00101-5
Jeena, M. (1998). Teachers' mental health status, stress levels and incidence of burnout during a period of change and reorganization within the South African Education System. Unpublished master's thesis. University of Natal, Durban, South Africa.

Luk, A.L., Chan, B.P.S., Cheong, S.W., \& Ko, S.K.K. (2010). An exploration of the burnout situation on teachers in two schools in Macau. Social Indicators Research, 93(3), 489-502.

Maslach, C. (1982). Burnout, the cost of caring. New York: Prentice-Hall, Inc.

Maslach, C., \& Jackson, S.E. (1986). Maslach Burnout Inventory Manual. (2nd edn.). Palo Alto, CA: Consulting Psychologists Press.

Maslach, C., \& Jackson, S.E. (1985). Patterns of burnout among a national sample of public contact workers. Journal of Health and Human Resources Administration, 7, 189-212.

Maslach, C., Jackson, S.E. \& Leiter, M.P. (1996). Maslach Burnout Inventory Manual. (3rd edn.). Palo Alto, CA: Consulting Psychologists Press.

McCormick, J. (2011). Teachers' attributions for stress and their relationships with burnout. International Journal of Educational Management, 25, 278-293.

McDermott, D. (1984). Professional burnout and its relation to job characteristics, satisfaction and control. Journal of Human Stress, 10, 79-85.

Mostert, K., \& Rothmann, S. (2006). Work-related well-being in the South African Police Service. Journal of Criminal Justice, 34(5), 479-491.

Purvanova R.K., \& Muros, J.P. (2010). Gender differences in burnout: A meta-analysis. Journal of Vocational Behavior, 77, 168-185

Pedrabissi, L., \& Rolland, J.P. (1993). Stress and Burnout among Teachers in Italy and France. Journal of Psychology, 127(5), 529-535. http://dx.doi.org/10.1080/00223 980.1993.9914889, PMid:8271230

Pines, A.M. (2002). Teacher burnout: A psychodynamic existential perspective. Teachers \& Teaching: Theory \& Practice, 8(2), 121-140.

Rakovec-Felser, Z. (2011). Professional Burnout as the State and Process - What to Do? Collegium Antropologicum, 35, 577-585.

Sadiwalla, N. (2004). Coping strategy as a moderator in the relationship between stressors and burnout in Hospice Workers. Unpublished master's thesis, University of the Free State, Bloemfontein, South Africa.

SAS User's Guide: statistics version. 5th edn. [Computer software] (1985). Cary, NC: SAS Institute.

Schaufeli W.B., \& Enzmann, D. (1998). The burnout companion to study and practiceA critical analysis. London: Taylor \& Francis.

Schermuly, C.C., Schermuly, R.A., \& Meyer, B. 2011. Effects of vice-principals' psychological empowerment on job satisfaction and burnout. International Journal of Educational Management, 25, 252-264.

Sears, S.J., \& Navin, S.L. (1983). Stressors in school counseling. Education, 103, 333337.

Skaalvik, E.M., \& Skaalvik, S. (2011). Teacher job satisfaction and motivation to leave the teaching profession: Relations with school context, feeling of belonging and the teaching profession: Relations with school context, feeling of belonging,
emotional exhaustion. Teaching and Teacher Education, 27(6), 1059-1069.

Smith, D., \& Leng, G.W. (2003). Prevalence and sources of burnout in Singapore secondary school physical education teachers. Journal of Teaching in Physical Education, 22(2), 203-218.

Smit, J. (2007). The influence of stressors and coping strategies on burnout and compassion fatigue among health care professionals. Unpublished doctoral dissertation. , University of the Free State, Bloemfontein, South Africa.

SPSS User's Guide. [Computer software] (1983). New York: SAS Incorporated.

Tabachnick, B.G., \& Fidell, L.S. (1989). Using multivariate statistics. (2nd edn.). New York: Harper \& Row.

Tynjälä, P., \& Heikkinen, H.L.T. (2011). Beginning teachers' transition from pre-service education to working life. Theoretical perspective and best practices. Zeitschrift für Erziehungswissenschaft, 14, 11-35.

Vandenberghe, R., \& Huberman, A.M. (1999). Understanding and preventing teacher burnout. Cambridge: Cambridge University Press. http://dx.doi.org/10.1017/ CB09780511527784

Vanheule, S. (2001). Burnout and psychoanalysis: A Freudo-Lacanian point of view. Journal for the Psychoanalysis of Culture and Society, 6(2), 265-270.

Van der Linde, A.H., Van der Westhuizen, P.C., \& Wissing, M.P. (1999). Burnout in female educators. South African Journal of Education, 19(3), 192-196.

Wheeler, D.L., Vassar, M., Worley, J.A., \& Barnes, L L.B. (2011). A Reliability Generalization Meta-Analysis of Coefficient Alpha for the Maslach Burnout Inventory. Educational and Psychological Measurement, 7, 231-244.

Wolters, C.A., \& Daugherty, S.G. (2007). Goal structures and teachers' sense of efficacy: Their relation and association to teaching experience and academic level. Journal of Educational Psychology, 99, 181-193.

Vilakazi, S.A. (2005). Burnout syndrome in the teaching profession. Unpublished master's thesis. KwaDlangezwa, University of Zululand, Zululand.

Yildirim, I. (2008). Relationhips between burnout, sources of social support and sociodemographic variables. Social Behaviour and Personality: an international journal, 36, 603-616. 